(C) 2016 IEEE. Personal use of this material is permitted. Permission from IEEE must be obtained for all other uses, in any current or future media, including reprinting/republishing this material for advertising or promotional purposes, creating new collective works, for resale or redistribution to servers or lists, or reuse of any copyrighted component of this work in other works.

\title{
In-situ monitoring of moisture ingress in PV modules using digital humidity sensors
}

\author{
M. Jankovec, F. Galliano, E. Annigoni, H. Y. Li, F. Sculati-Meillaud, L. E. Perret-Aebi, C. Ballif, M. Topič, Senior \\ Member, IEEE
}

\begin{abstract}
A new in-situ moisture monitoring technique for PV modules is proposed using miniature digital humidity and temperature sensors. The sensors were embedded in three different ethylene-vinyl-acetate (EVA) stacks and proved to be resistant to lamination conditions. The fact that they are in direct contact to EVA does not affect their performance since their saturated relative humidity $(\mathrm{RH})$ reading is proportional to the external RH in the air. By exposing the sensors to elevated temperature and RH conditions, water vapor transmission rate (WVTR) of the backsheet and diffusion coefficient of the EVA can be determined. Obtained coefficients agree with reference values within their measurement uncertainties. Besides determining material moisture ingress properties, this monitoring technique is also applicable for long-term outdoor PV module monitoring. It shall provide valuable location and installation specific information of RH and temperature stress conditions, especially as a feedback information to manufacturers of materials and PV modules.
\end{abstract}

Index Terms - Instrumentation and measurement, Measurement techniques, Humidity measurement, Photovoltaic modules

\section{INTRODUCTION}

$\mathrm{P}$ HOTOVOLTAIC (PV) modules are installed all over the world in various climatic and environmental conditions. During their operation they face different stress factors such as extreme temperatures, high moisture, UV irradiation, wind, snow, hail, sand, salt and others, degrading their performance [1]-[3]. Although PV modules are certified according to currently valid IEC standards, granted certificates do not fully guarantee their lifetime performance [4], [5]. In particular, moisture ingress represents an important performance degradation factor, which is strongly influenced by the PV module's configuration, encapsulants, installation type and location [6], [7]. Water vapor in form of particles or bubbles affects the level of irradiance entering the cells and changes modules' performance instantly [8] whereas moisture ingress into the PV module causes hydrolysis of polymeric components, corrosion of glass and metallic parts like solar cells' fingers and tabbing ribbons [9], [10]. Elevated moisture and temperature are strongly affecting potential induced degradation (PID) rates [11] and are strongly correlated to leakage currents [12]. Combining heat and UV irradiation, moisture can also cause coloration of encapsulants or affect the adhesion between the different layers.

Hence, to assess the long term performance of PV modules it is significant to be able to predict the level of water ingress in them, where, besides climatic and installation conditions, the choice of encapsulants plays a crucial role. By using previously determined properties of moisture diffusion and solubility of used materials, it is possible to simulate the moisture ingress in PV modules using approximate analytical relations [13], [14] or Finite Element Modelling (FEM) [15]. Some attempts of in-situ moisture measurement methods have also been reported using different self-made moisture sensors with combination of external impedance spectroscopy instruments [16]-[18]. Although they give results that are consistent with simulations they all require thorough calibration procedures and cumbersome instrumentation. Till now, the use of commercially available humidity sensors was very limited mainly by the large size of the sensors. Thanks to the rapid progress of integrated circuits miniature calibrated digital sensors are now commercially available.

In this paper we propose a new in-situ PV module moisture measurement method based on an array of commercial humidity sensors SHT25 from Sensirion. This type of sensors work on a capacitive measurement principle using polymer dielectric that provide accurate temperature and humidity readings with full in-chip calibration and temperature

Manuscript received Month XX, 2015. Slovenian support was provided by the Slovenian Research Agency under the Research Programme P2-0197 and Project J2-7105.

M. Jankovec and M. Topič are with the University of Ljubljana, Faculty of Electrical Engineering, SI-1000 Ljubljana, Slovenia (e-mail: marko.jankovec@fe.uni-lj.si, marko.topic@,fe.uni-lj.si).

E. Annigoni, F. Sculati-Meillaud and C. Ballif are with the École Polytechnique Fédérale de Lausanne (EPFL), Institute of Microengineering, Photovoltaics and Thin Film Electronics Laboratory, CH-2000 Neuchâtel, Switzerland (e-mail: eleonora.annigoni@epfl.ch, fanny.sculati-meillaud@epfl.ch, christophe.ballif@epfl.ch)

H. Y. Li, F. Galliano, L. E. Perret-Aebi and C. Ballif are with CSEM, PV-Center, CH-2000 Neuchâtel, Switzerland (e-mail: hengyu.li@csem.ch, laureemmanuelle.perret@csem.ch, christophe.ballif@.csem.ch) 
compensation [19]. Since the sensors are packed in a "Dual Flat No leads" (DFN) package with $3 \mathrm{~mm}$ x $3 \mathrm{~mm}$ footprint and $1.1 \mathrm{~mm}$ height, their introduction into the PV module stack are viable and presents minimal impact while offering one of the lowest absolute $\mathrm{RH}$ measurement uncertainty $<2 \% \mathrm{RH}$ in the range from $10 \% \mathrm{RH}$ to $90 \% \mathrm{RH}$.

\section{EXPERIMENT}

\section{A. Humidity sensors SHT25}

Humidity sensors SHT25 are integrated sensors based on a CMOSsens ${ }^{\circledR}$ technology [20]. This technology utilizes capacitive sensing principle using a capacitor that contains polymer dielectric which absorbs or releases water according to the surrounding humidity. The change of the capacitance is sensed by an integrated readout electronics. A combination of a temperature sensor, on-board calibration data memory and signal processing in the same chip provides calibrated and temperature compensated data via a digital Inter-Integrated Circuit $\left(\mathrm{I}^{2} \mathrm{C}\right)$ communication interface. Sensor package dimensions are shown in Fig. 1 where the top rectangular opening represents the entrance to the moisture sensitive area, while soldering pads are located on the bottom at both lateral edges.
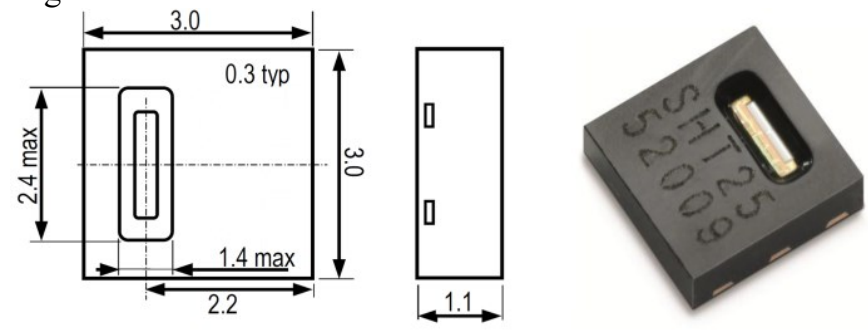

Fig. 1. Sensirion SHT25 digital humidity sensor [19]. Dimensions are in millimeters.

Typical temperature measurement uncertainty is $\pm 0.2{ }^{\circ} \mathrm{C}$ in the range between $0{ }^{\circ} \mathrm{C}$ and $60^{\circ} \mathrm{C}$, while in the overall measurement range from $-40^{\circ} \mathrm{C}$ to $+120^{\circ} \mathrm{C}$ it is confined within $\pm 0.7{ }^{\circ} \mathrm{C}$. Relative humidity (RH) measurement uncertainties that depend strongly on temperature and humidity are summarized in Fig. 2. The sensors work most stably in a normal measurement range where they exhibit outstanding RH measurement uncertainty typically as low as $\pm 1.8 \% \mathrm{RH}$. In addition to somewhat worse accuracy outside the normal operation range (typically from $\pm 2 \% \mathrm{RH}$ to $\pm 3.5 \% \mathrm{RH}$ ), a long term exposure to $\mathrm{RH}$ conditions above $80 \% \mathrm{RH}$ may temporarily offset the $\mathrm{RH}$ reading $(+3 \% \mathrm{RH}$ after $60 \mathrm{~h}$ ), as stated in the datasheet [19].

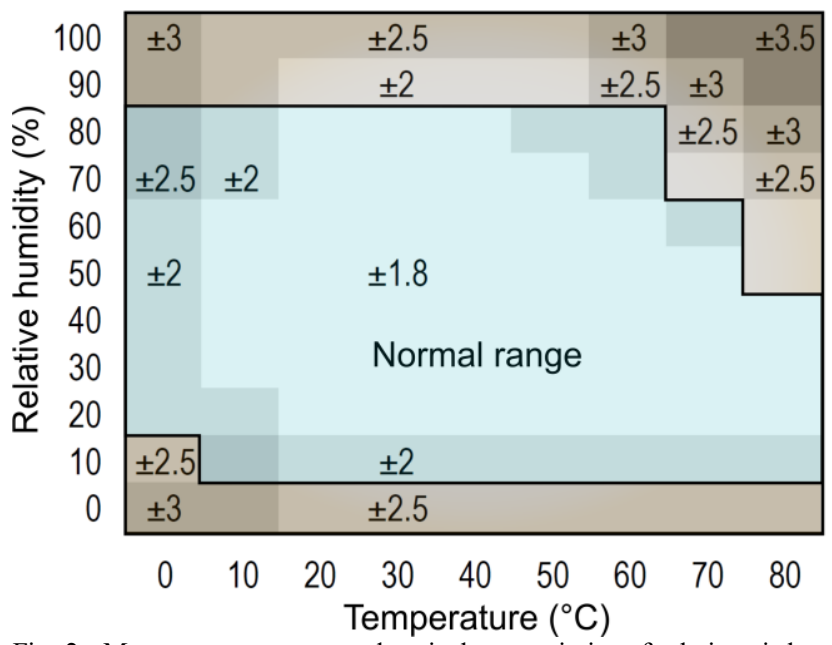

Fig. 2. Measurement ranges and typical uncertainties of relative air humidity measurement in \%RH [19].

\section{B. Sensor strips}

A custom sensor strip was designed for mechanical support and electrical connections to the sensors that can hold up to 10 equally spaced sensors in one row. The sensor strip is basically a Printed Circuit Board (PCB) based on a FR-4 (Epoxy resin material reinforced by 8 layers of glass fiber cloth) core material covered by $35 \mu \mathrm{m}$ thick copper foil on both sides. The copper foil was patterned to provide isolated electrical routes from the sensors to the edge connector on the right hand side of the strip, as shown in Fig. 3. A $0.5 \mathrm{~mm}$ pitch flat ribbon cable was soldered to the edge connector providing connection to external readout electronics.

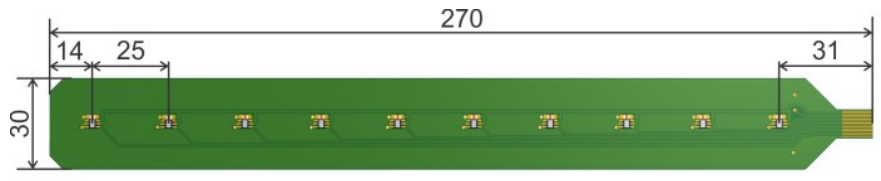

Fig. 3. Sensor strip from bottom side with measures in milimeters. Sensors are positioned equidistantly with $25 \mathrm{~mm}$ pitch in the middle along the strip.

A square slot the size of the sensor's footprint was cut out of the PCB for each sensor. The sensors were placed in the prepared slots and their pads were soldered across the edges of the slots to the corresponding connection lines on the bottom side of the PCB. Each slot was widened on one side just enough to provide the space for an additional $100 \mathrm{nF}$ capacitor (case size 0805) next to each sensor for power supply decoupling. Since the thickness of the PCB is $0.5 \mathrm{~mm}$ and sensors are thicker $(1.1 \mathrm{~mm})$, we aligned them with the top side of the $\mathrm{PCB}$, providing a flat surface on the sensing side as shown in Fig. 4.
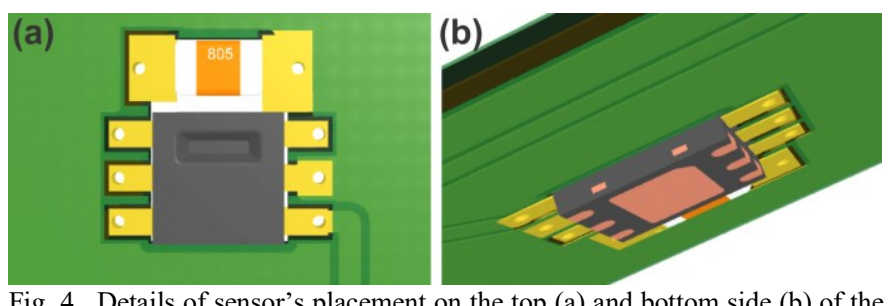

Fig. 4. Details of sensor's placement on the top (a) and bottom side (b) of the PCB. On top side of the PCB it is aligned with the surface of the PCB whereas 
on the bottom side of the PCB it sticks out for $0.6 \mathrm{~mm}$. Additional $100 \mathrm{nF}$ capacitor is placed in the slot next to the sensor for power supply decoupling.

For measurement data reading we developed an electronic interface capable of connecting three sensor strips in parallel. This enables temperature and RH reading of up to 30 sensors simultaneously using general call synchronization technique followed by a data fetching, minimizing total scan time down to $1 \mathrm{~s}$. Data are transferred to a personal computer via Universal Serial Bus (USB) interface and stored for post analyses.

\section{Preliminary EVA/EVA stack experiment}

Humidity sensors SHT25 are initially calibrated solely for RH measurements in the air thus their performance in direct contact to different encapsulants is generally not known. The manufacturer also states that one has to be very careful when exposing sensors to different environments containing gasses not commonly present in the air. To test and evaluate the performance of the laminated humidity sensors technique, the simplest possible stack was laminated, consisting of only two layers of ethylene-vinyl-acetate (EVA) on each side of the sensor strip (Fig. 5). This stack arrangement allows quick moisture exchange between the air and the sensor with the least unknown variables. Altogether, four sensor strips were assembled with four sensors each. Three sensors on one side of the strip were laminated in the EVA/EVA stack while the fourth sensor on the other side of the strip was kept unlaminated for direct air RH measurement.

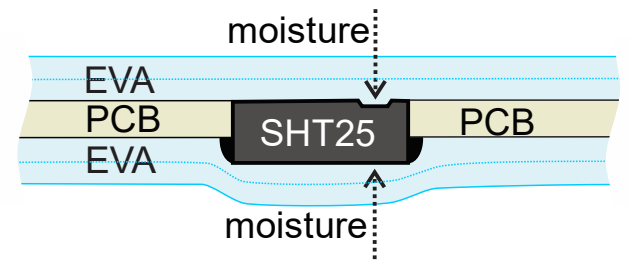

Fig. 5. EVA/EVA stack experiment configuration. Arrows denote main moisture ingress paths.

The sensor strips were put in a climate chamber KK-2310 CHLT, which has a stated RH temporal accuracy better than $\pm 3 \% \mathrm{RH}$. The temperature was set to $80^{\circ} \mathrm{C}$ while the $\mathrm{RH}$ was increased from $30 \% \mathrm{RH}$ to $90 \% \mathrm{RH}$ in $10 \% \mathrm{RH}$ steps and finally to $95 \% \mathrm{RH}$. Each step was held long enough to provide stable $\mathrm{RH}$ for $1 \mathrm{~h}$ within the range of $\pm 3 \% \mathrm{RH}$ according to the set value. Since the manufacturer of the climate chamber does not specify the spatial RH inhomogeneity which can vary as high as $\pm 5 \% \mathrm{RH}$ in similar chambers, the reference air RH was measured separately in the vicinity of the sensor strips using a calibrated sensor (FHA646 from Almemo) with the RH measurement uncertainty of $\pm 3 \% \mathrm{RH}$ (expanded uncertainty factor $k=2$ ). Measurement data were acquired simultaneously in $1 \mathrm{~min}$ intervals.

\section{Glass/EVA/backsheet stack experiment}

The purpose of this experiment was to evaluate the applicability of the proposed method to determine the moisture diffusion properties of the backsheet material. Here a classical PV module stack was laminated consisting of glass, two pairs of EVA sheets on each side of the sensor strip and a backsheet. Two equal stacks the size of $40 \mathrm{~cm} \times 20 \mathrm{~cm}$ were laminated, each containing one sensor strip equipped with three sensors for redundancy.

Comparing the vertical and lateral moisture diffusion path distances it is plausible to assume that the moisture predominantly diffuses in vertical direction through the backsheet. Here the glass is presumed as impermeable.

\begin{tabular}{l|l|l}
\multicolumn{2}{c}{ moisture } & \\
\hline backsheet & \\
\hline EVA & & \\
\hline PCB & SHT25 & PCB \\
\hline EVA & glass \\
\hline \multicolumn{2}{ll}{} \\
\hline \multicolumn{2}{ll}{} \\
\hline
\end{tabular}

Fig. 6. Glass/EVA/backsheet stack experiment configuration. Arrow denotes main moisture ingress path vertically through the backsheet.

Both stacks were put into a climate chamber and exposed to damp-heat (DH: $T=85^{\circ} \mathrm{C}, R H=85 \% \mathrm{RH}$ ) conditions for $100 \mathrm{~h}$.

\section{E. Glass/EVA/glass stack experiment}

In this experiment, two $40 \mathrm{~cm} \times 40 \mathrm{~cm}$ glass/glass $\mathrm{PV}$ module stacks were laminated with two layers of EVA on each side of the sensor strip. Assuming the glass is impermeable, moisture penetrates through the EVA laterally from edges which are fully exposed to the environment as shown in Fig. 7. Hence with this experiment moisture ingress properties of EVA are investigated.

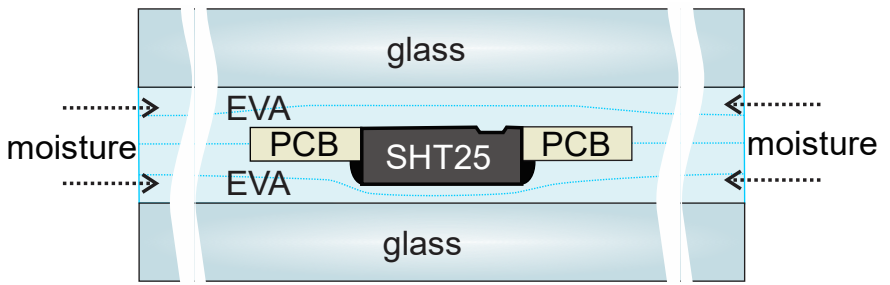

Fig. 7. Glass/EVA/glass stack experiment configuration. Arrows denote main moisture ingress paths laterally through EVA layers from the edges.

Fig. 8 shows sensor strip placement for both glass/EVA/glass stacks. In the sample A it is placed in parallel to the edges and in the sample B diagonally from one corner to the center. Since both sensor strips are fully equipped with 10 sensors each, the sensor strip in sample A extends across the center with sensor $\mathrm{S} 7$ at the center while in the sample B sensor S10 is positioned at the center.
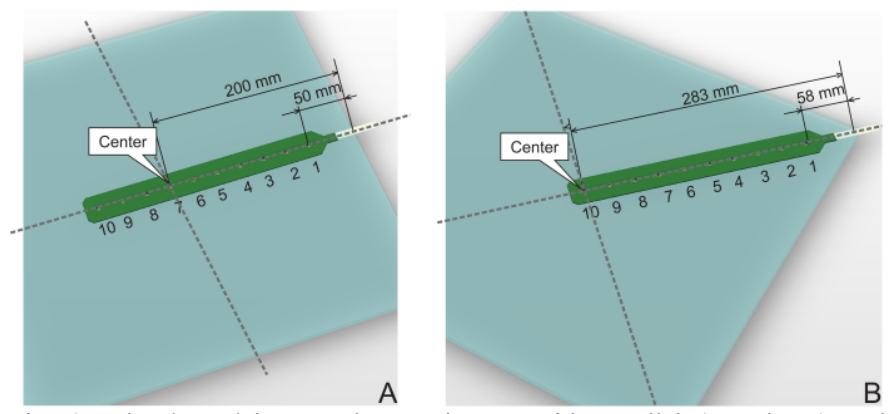

Fig. 8. Glass/EVA/glass stack experiments with parallel (sample A) and diagonal (sample B) placement of the sensor strip. 
In both samples the sensor strip is connected across the edge of the stack to the outside readout electronics via a thin 14-leads $8.5 \mathrm{~mm}$ wide and $0.4 \mathrm{~mm}$ thick ribbon cable (Temp-lex $30 \mathrm{AWG})$. This cable was used because it can resist typical lamination temperatures up to $200^{\circ} \mathrm{C}$ by using Fluorinated Ethylene Propylene (FEP) insulation material [21]. Small cable dimension assured minimal impact to moisture ingress properties at the place where it enters the laminated stack.

As in the previous experiments both samples were exposed to damp-heat (DH: $T=85^{\circ} \mathrm{C}, R H=85 \% \mathrm{RH}$ ) conditions, but since the moisture diffusion path from the edges to the middle of the stack is much longer than in the previous case, the test was conducted for $2500 \mathrm{~h}$.

All of the stacks were prepared by a standard lamination procedure according to the manufacturer's recommended recipe. Before the lamination, all sensor strips were baked in the oven at $80^{\circ} \mathrm{C}$ for at least $3 \mathrm{~h}$ to evaporate the water that may have existed in the FR-4. In Table 1, materials' thicknesses and moisture ingress data (diffusion coefficient $\mathrm{D}$, water vapor transmission rate WVTR and saturation water content $c_{s}$ ) are summarized. Data at $30{ }^{\circ} \mathrm{C}, 40{ }^{\circ} \mathrm{C}$ and $50{ }^{\circ} \mathrm{C}$ were determined by a Mocon experiment using PERMATRAN-W Model 3/33. Data at $85{ }^{\circ} \mathrm{C}$ were extrapolated using the Arrhenius law dependency.

TABLE 1

MAIN PROPERTIES OF MATERIALS USED.

\begin{tabular}{llllll}
\hline \hline Material & $\begin{array}{l}\text { thickness } \\
(\mathrm{mm})\end{array}$ & $\begin{array}{l}\boldsymbol{T} \\
\left({ }^{\circ} \mathrm{C}\right)\end{array}$ & $\begin{array}{l}\boldsymbol{D} \\
\left(\mathrm{m}^{2} / \mathrm{s}\right)\end{array}$ & $\begin{array}{l}\boldsymbol{W V T} \boldsymbol{R} \\
\left(\mathrm{kg} / \mathrm{m}^{2} / \mathrm{s}\right)\end{array}$ & $\begin{array}{l}\boldsymbol{c}_{\boldsymbol{s}} \\
\left(\mathrm{kg} / \mathrm{m}^{3}\right)\end{array}$ \\
\hline EVA & & 30 & $4.8 \cdot 10^{-11}$ & $7.2 \cdot 10^{-8}$ & 1.8 \\
EVASKY S88 & 0.48 & 40 & $8.6 \cdot 10^{-11}$ & $1.5 \cdot 10^{-7}$ & 2.0 \\
(Bridgestone) & & 50 & $1.5 \cdot 10^{-10}$ & $2.8 \cdot 10^{-7}$ & 2.2 \\
& & $85^{*}$ & $8.1 \cdot 10^{-10}$ & - & 3.2 \\
\hline Backsheet & & 30 & $8.2 \cdot 10^{-13}$ & $1.3 \cdot 10^{-8}$ & - \\
DUNSOLAR PPE+ & 0.36 & 40 & $1.5 \cdot 10^{-12}$ & $2.5 \cdot 10^{-8}$ & - \\
(Dunmore) & & 50 & $3.1 \cdot 10^{-12}$ & $4.6 \cdot 10^{-8}$ & - \\
& & $85^{*}$ & $2.1 \cdot 10^{-11}$ & $3.0 \cdot 10^{-7}$ & - \\
\hline \hline
\end{tabular}

*Data at $85^{\circ} \mathrm{C}$ are extrapolated from measured points at $30^{\circ} \mathrm{C}, 40^{\circ} \mathrm{C}$ and $50^{\circ} \mathrm{C}$ using Arrhenius law dependency.

\section{RESULTS}

\section{A. Preliminary test of the EVA/EVA stack}

Results of the preliminary EVA/EVA stack experiment are shown in Fig. 9. Measurement values of the SHT25 sensors that are exposed to the air closely follow the reference $\mathrm{RH}$ measurement up to $90 \% \mathrm{RH}$, where an additional drift up to $+5 \% \mathrm{RH}$ appears. Thus at the highest set humidity of $95 \% \mathrm{RH}$ sensors give air humidity results even over $100 \% \mathrm{RH}$. Please note that the reference RH value in the air which was measured by an independent sensor in the vicinity of the stacks shows systematic positive bias with regard to the values set by climatic chamber which were set in $10 \% \mathrm{RH}$ steps from $30 \% \mathrm{RH}$ to $90 \% \mathrm{RH}$ and finally to $95 \% \mathrm{RH}$. The RH set error at the place of the stacks increases with the set RH value but stays below $4 \%$ RH. Temperature monitoring results were very stable within the stated uncertainly of $\pm 0.5^{\circ} \mathrm{C}$ and they are not shown in the following graphs for clarity.

The RH measurement results of the laminated SHT25 sensors show that EVA moisturizes very quickly at $80{ }^{\circ} \mathrm{C}$ as expected and thus quickly follows the changes of the external RH. Further, the RH readings of the laminated sensors in the same stack or even between stacks are very consistent. And most importantly, the internal $\mathrm{RH}$ readings follow the external $\mathrm{RH}$ with some delay but saturate close to the air $\mathrm{RH}$ value at the end of each step.

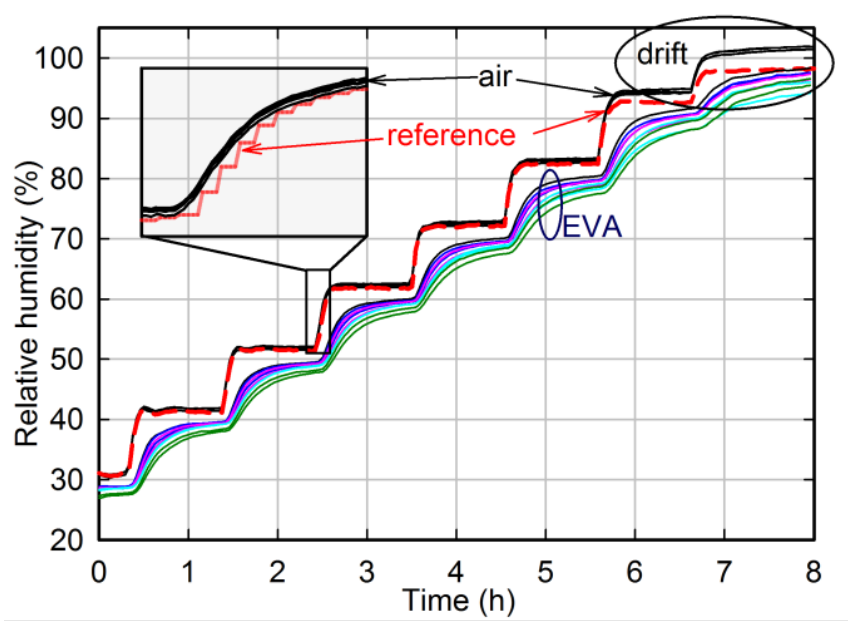

Fig. 9. Measurement results of the preliminary EVA/EVA stack experiment. Reference value (dashed line) was measured by an independent sensor in the vicinity of the stacks. Individual RH readings of all external sensors are shown as full black lines (air) while RH readings of laminated SHT25 sensors are shown as colored full lines (EVA). The inset presents the enlarged portion of the transition between the two successive RH steps which indicates adequate response speed of the SHT25 sensors.

\section{B. Glass/EVA/backsheet stack experiment}

The results of the glass/EVA/backsheet stack experiment in a steady DH conditions are shown in Fig. 10. The control of the air RH at $85 \%$ (measured by a separate SHT25 sensor) was performed well, except at the beginning where a transient behavior after closing the chamber is observed. After approximately $40 \mathrm{~h}$ when a steady state of $85 \% \mathrm{RH}$ was reached a small positive drift appears in the sensor in the air. Much more pronounced drift was already observed in the range above $90 \%$ RH (see Fig. 9).

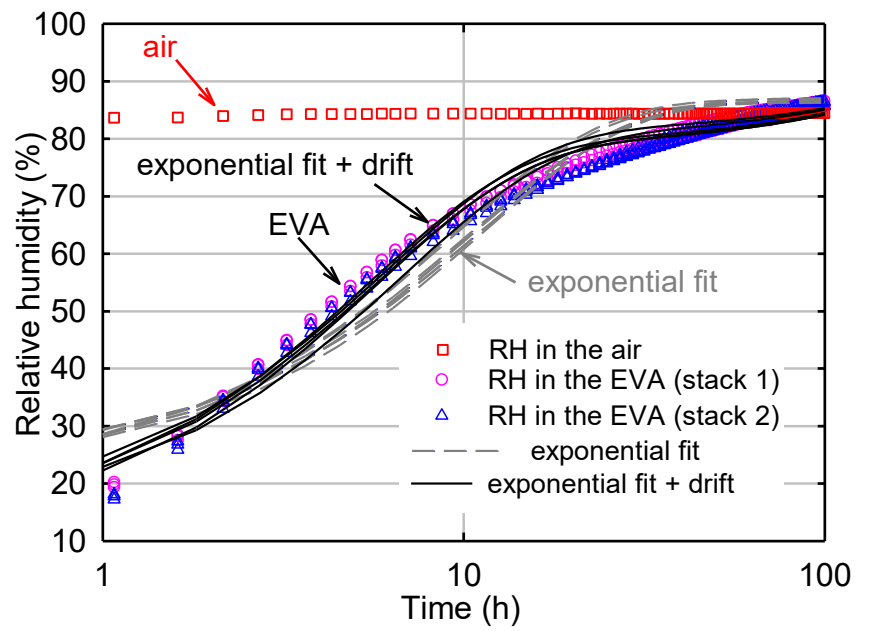

Fig. 10. Measurement results of all sensors in both glass/EVA/backsheet stack experiments in steady DH conditions. RH readings of individual sensors are presented by symbols and their corresponding fitting results by lines.

Similarly to the preliminary test, the RH readings are very consistent for the sensors in the same stack as well as for the sensors in different stacks. The RH values increase in 
exponential fashion and saturates close to the value of the external RH.

Assuming that moisture enters mainly perpendicularly through the backsheet and the EVA to the sensor, we can apply the onedimensional Fick's diffusion model to describe the water content time dependence at the location of the sensors. According to [14], the Fick's differential equation can be simplified with some reasonable assumptions to

$\frac{d c}{d t}=\frac{W V T R_{B S}}{c_{S} \cdot d}\left(c_{e x}-c\right)$

and solved analytically, leading to the following solution

$c(t)=c_{0}+\left(c_{e x}-c_{0}\right) \cdot\left(1-e^{-\frac{W V T R_{B S}}{c_{S} \cdot d} \cdot t}\right)$,

where $c$ is the water concentration in the EVA measured by our laminated sensors, $c_{0}$ is the initial water concentration in the EVA, $c_{e x}$ is the concentration of water that would be in the EVA at equilibrium with the air, which is presumed to be constant, $c_{s}$ is the saturation water concentration in the EVA, $d$ is total thickness of the four EVA sheet layers used in the stack and $W V T R_{B S}$ is the water vapor transmission rate of the backsheet in saturation conditions.

We fitted all of the acquired RH data to (2) using Least Mean Square method, where $W V T R_{S B}$ was free parameter. Fitting results are shown in Fig. 10 with dashed gray lines. Since the fit was not very good, we added a linear term "drift $\cdot t$ " to (2) to model the observed drift of the sensors. These fits are denoted by full black lines in Fig. 10. The obtained fitting parameters are presented in the discussion section.

\section{Glass/EVA/glass stack experiment}

Results of the glass/EVA/glass stack experiment in steady DH conditions for samples A and B are shown in Fig. 11 and Fig. 12 , respectively. Since the moisture enters from the edges of the stack only it takes much longer to reach the sensors deeper in the stack. Thus, in contrast to the previous glass/EVA/backsheet experiment which lasted for $100 \mathrm{~h}$, this experiment requested more than $1000 \mathrm{~h}$ to observe a significant humidity increase at the center of the stack. Thus we carried out this experiment for $2500 \mathrm{~h}$. During this time, the drift in the air RH readings measured by a separate SHT25 sensor is clearly evident although the chamber maintained constant DH conditions according to the reference measurement. Moisture reaches each sensor individually starting from S1 which is closest to the edge and continuing to the sensors that are deeper in the stack. In Fig. 11 results of the sensors S1-S7, being S7 in the center of the sample A are shown. Since the sensors S8-S10 are symmetrically placed on the other side from the center with respect to the sensors S6-S4 their readings are not shown here. Nevertheless they will be presented later in Fig. 13 to confirm that the implementation of the sensor strip does not affect the water diffusion through the bulk EVA material. In case of sample B data of all 10 sensors are presented in Fig. 12.

In contrast to the glass/Eva/backsheet stack here we can apply lateral two-dimensional (2D) Fick's diffusion problem, which can be also solved analytically making some reasonable assumptions [14]. A 2D time solution for water concentration in each point of the EVA in the stack $c(x, y, t)$ can be expressed in the form of infinite sum of harmonic terms

$\frac{c(x, y, t)-c_{S}}{c_{0}-c_{S}}=\frac{16}{\pi^{2}} \sum_{m=0}^{\infty} \frac{1}{2 m+1} \sin \left(\frac{(2 m+1) \pi}{l_{x}} x\right) e^{-\left(\frac{(2 m+1) \pi}{l_{x}}\right)^{2} D_{E V A} t}$. $\sum_{n=0}^{\infty} \frac{1}{2 n+1} \sin \left(\frac{(2 n+1) \pi}{l_{y}} y\right) e^{-\left(\frac{(2 n+1) \pi}{l_{y}}\right)^{2} D_{E V A} t}$,

where only two EVA material properties are used, i.e. the diffusion constant $D_{E V A}$ and the saturation water concentration $c_{s}$. Besides already mentioned parameters in (2) only lateral dimensions of the stack $\left(l_{x}, l_{y}\right)$ are present here. Fitted curves using (3) are in very good agreement with the measured data for all sensors in both stacks, except for sensor S1 which is closest to the edge of the stack. RH values given by the sensor $\mathrm{S} 1$ rapidly increase from the very beginning of the test although the distance of this sensor from the edge is $50 \mathrm{~mm}$ in sample A and $58 \mathrm{~mm}$ in sample B. This indicates that the water vapor diffuses almost instantly to the sensor S1 from the closest edge most probably due to a bad adhesion of the EVA to the FEB ribbon cable. Additionally, in the case of the sample B the RH values of S1 increase beyond expected limits without saturation. It seems that $\mathrm{S} 1$ exhibits much higher drift when operating outside normal range than the sensors in the air (that is above $60 \% \mathrm{RH}$ at $85^{\circ} \mathrm{C}$ ). This phenomenon can be attributed to the fact that sensor S1 is exposed to the highest RH among all laminated sensors for very long time causing unexpected sensor failure. This failure could be triggered by some interaction of the sensor to the released gases from the EVA or could be just a coincidence.

Fig. 13 shows RH spatial profile at different times for sample A including all 10 sensors. Symmetrical shape of the spatial profile around sensor S7 at the center of the stack indicates there is no favorable moisture ingress path along the surface of the sensor strip i.e. water diffuses equally from all edges towards the center regardless the presence of the sensor strip on one side.

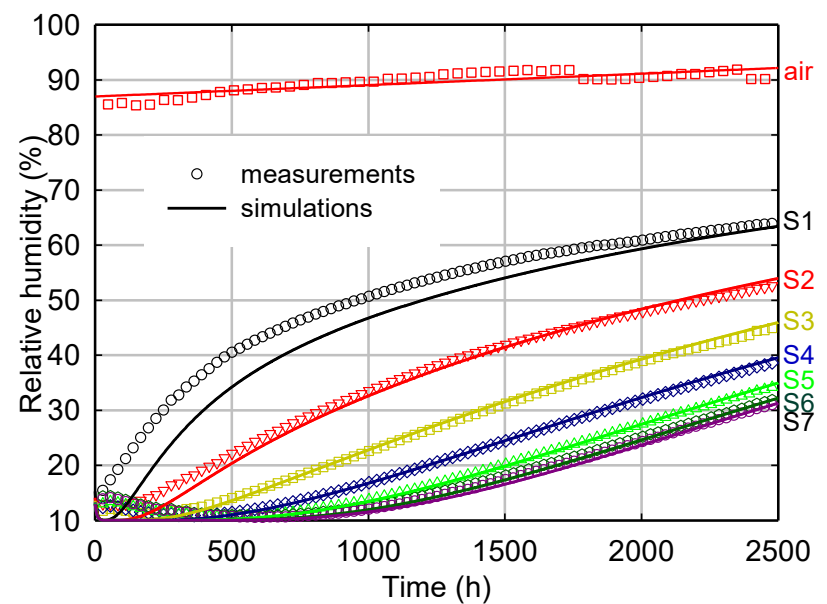

Fig. 11. Measurement results of the glass/EVA/glass stack experiment for the sample A in steady DH conditions. Measurements are presented by symbols and fitting results with lines. 


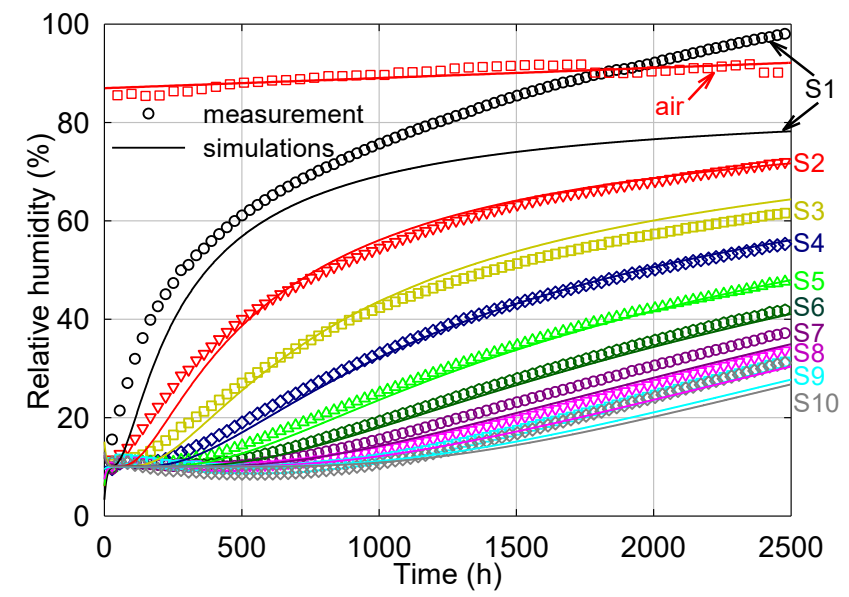

Fig. 12. Measurement results of the glass/EVA/glass stack experiment for the sample B in steady DH conditions. Measurements are presented by symbols and fitting results with lines.

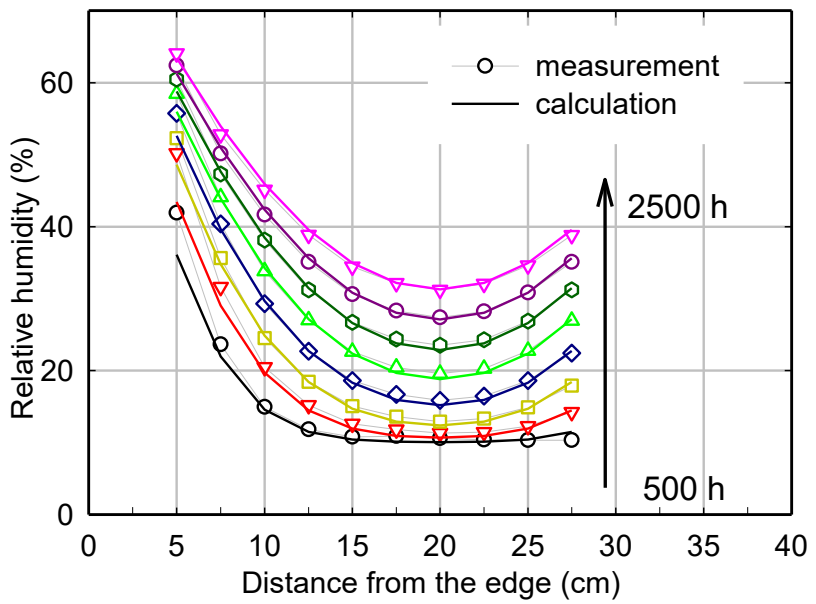

Fig. 13. Spatial profile of the RH readings for the sample A in steady DH conditions at different times. Measurements are presented by symbols and fitting results with lines.

\section{DISCUSSION}

The preliminary test using EVA/EVA stack showed that in normal operation conditions (denoted as normal range in Fig. 2) SHT25 sensors encapsulated in the EVA perform as well as in the air. They survive the lamination procedure without any observable impact on their performance. Furthermore, their RH reading is linearly proportional to the $\mathrm{RH}$ of the air, although there is no air present in the EVA since it is presumably sucked out of the stack during the lamination process. At least no air bubbles were observed in the laminate and as it is evident from the Fig. 14 the EVA pours in all openings including the entry to the active part of the SHT25 humidity sensor.
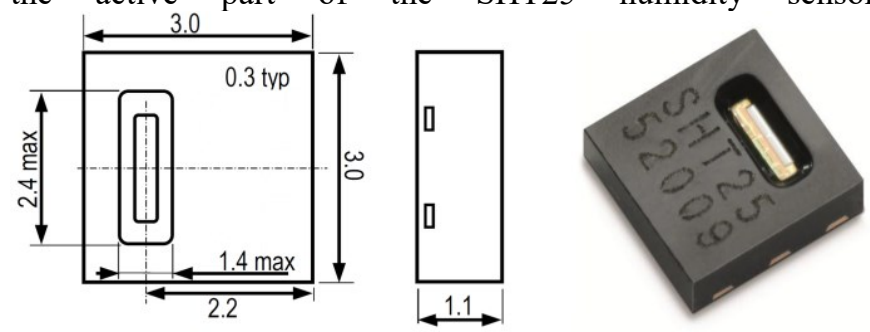

Therefore, we are quite certain that the EVA is in direct contact to the active capacitive sensing area of the laminated sensor.
The credibility of the proposed method for in-situ monitoring of water content in the PV modules is reinforced by the fact that all laminated sensors provide consistent measurements that are proportional to the $\mathrm{RH}$ values in the air.

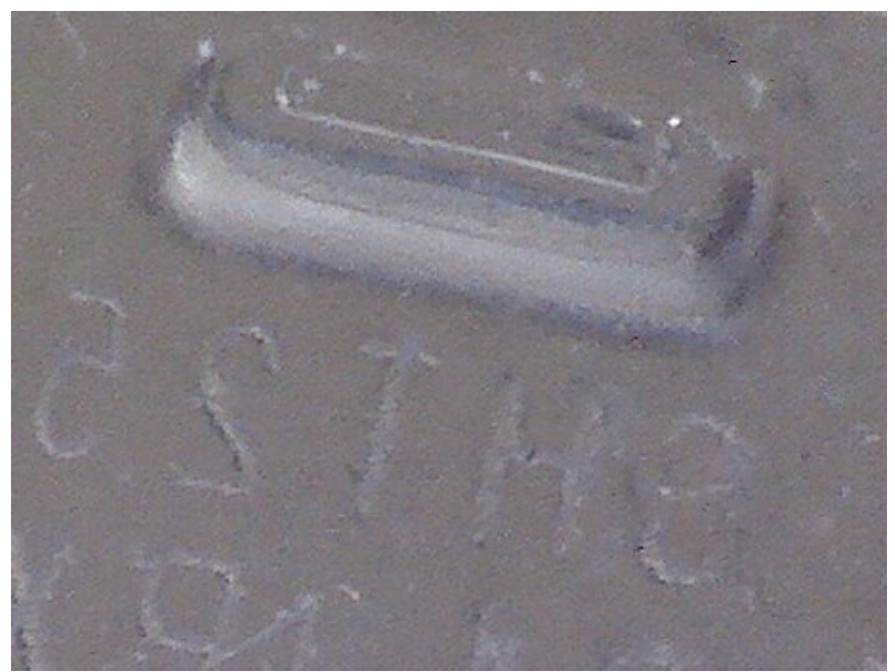

Fig. 14. Micrograph of the part of detached EVA foil above the SHT25 humidity sensor. A part of the EVA that poured into the opening of the active sensor area is seen as the elevated part. No traces of air bubbles are observed.

The experiments on sensors laminated in realistic PV stacks (glass/EVA/backsheet and glass/EVA/glass) showed that the SHT25 sensors can withstand a long period of elevated temperature and $\mathrm{RH}$ conditions as long they are exposed to $\mathrm{RH}$ values under $70 \% \mathrm{RH}$. Above that RH range they can exhibit much higher drift than in the air. The drift of the sensor in the air that was determined by a linear fit from the $2500 \mathrm{~h}$ experiment is $3.6 \% \mathrm{RH} / 1000 \mathrm{~h}$ which agrees with the drift, stated by the manufacturer if the sensor is exposed to $\mathrm{RH}$ above $80 \% \mathrm{RH}[19]$. As stated in the datasheet we have also observed, that the drift process is reversible. In Fig. 11 and Fig. 12 two small steps in the external $\mathrm{RH}$ reading (at $t=1750 \mathrm{~h}$ and $t=2400 \mathrm{~h}) \mathrm{can}$ be noticed. They correspond to short term openings of the climatic chamber, when the sensors in the air experience a sudden drop of temperature and RH (not shown in the graphs due to low sampling rate). During that time their readings were shifted to lower values, from which they started to slowly drift again when the chamber was closed and temperature and RH conditions were restored.

The drift observed in the EVA is higher. In the case of the sensor S1 laminated in the sample B (Fig. 12) it reaches $14.5 \% \mathrm{RH} / 1000 \mathrm{~h}$. Similar drift parameters $12-14 \% \mathrm{RH} / 1000 \mathrm{~h}$ were obtained by fitting the RH results in the EVA of the glass/EVA/backsheet stack to exponential equation (2) with additional linear term.

The drift of the laminated sensors in the EVA can be related to at least three mechanisms:

- slow absorption of water in the FR-4, which is not taken into account in the simplified diffusion model solution (Eq. 1)

- the effect of gasses released from the EVA that can affect the sensor readings

- the already observed drift due to exposing sensors outside normal operating conditions. 
These mechanisms are not yet characterized and thus any additional non-linear fitting with higher number of parameters would not add to better understanding of the processes going on inside the PV stack. The linear fit used is just the simplest approximation that should be upgraded to be valid for a longer time.

Nevertheless, the observed worse measurement uncertainty and drift when exposed to environment outside normal operating range conditions like $\mathrm{DH}$ does not limit the use of the sensors since such conditions are very unlikely to be reached during normal field operation of PV modules. Therefore, regarding temperature and $\mathrm{RH}$ conditions the presented measurement setup is expected to be suitable for long term outdoor monitoring applications of PV modules, such as in the case presented in Fig. 15, where both glass/EVA/backsheet stacks were mounted outdoors in order to monitor temperature and $\mathrm{RH}$ for longer time.

Preliminary outdoor monitoring results, presented in Fig. 16, show that the measured RH value in the EVA reaches steady value of $66 \% \mathrm{RH}$ after 20 days of outdoor exposure. This value corresponds to the mean external $\mathrm{RH}$ what is also the point made in [22]. Daily air RH variations are thus averaged out in the PV module since the half-time time of the diffusion process $t_{1 / 2}$ according to [14] equals:

$t_{1 / 2}=0.693 \frac{c_{S} \cdot d}{W V T R_{B S}}=4.3$ days,

where saturation water density for EVA $\left(c_{s}=1.5 \mathrm{~kg} / \mathrm{m}^{3}\right)$ and water vapor transmission rate of backsheet $\left(W V T R_{B S}=5.4\right.$. $10^{-9} \mathrm{~kg} / \mathrm{m}^{2} \mathrm{~s}$ ) were determined by extrapolation using Arrhenius law to the average temperature during the outdoor experiment $\left(T=18^{\circ} \mathrm{C}\right)$.

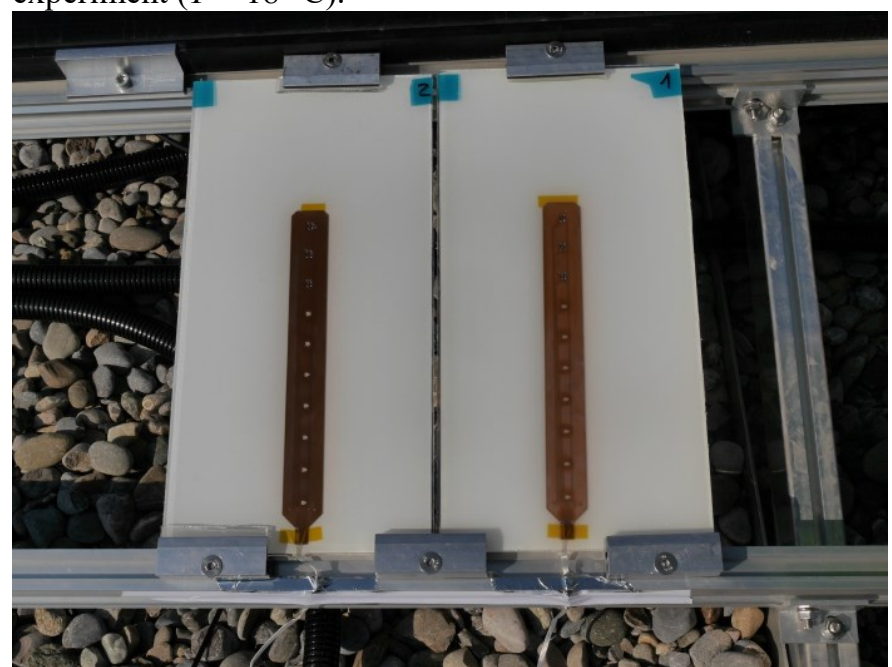

Fig. 15. Outdoor temperature and humidity monitoring setup of two glass/EVA/backsheet stacks.

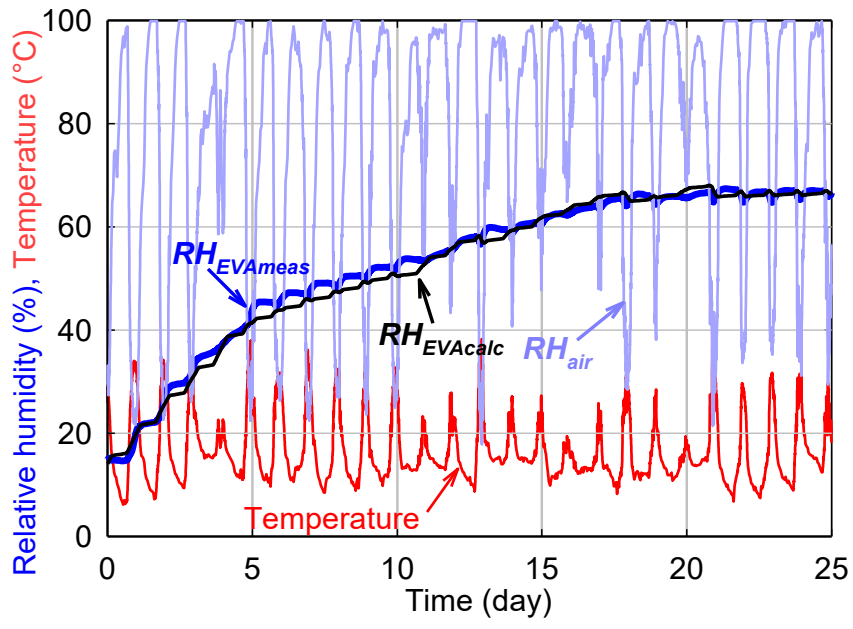

Fig. 16. Outdoor temperature and humidity monitoring results for one of two glass/EVA/backsheet stacks. Relative humidity measured in the EVA $\left(R H_{\text {EVAmeas }}\right)$ reaches steady value after 20 days of outdoor exposure. Calculated internal $\mathrm{RH}\left(R H_{\text {EVAcalc }}\right)$ agrees well with the measurement.

Although the actual temperature varied daily from $6^{\circ} \mathrm{C}$ to $38^{\circ} \mathrm{C}$ the half-time $t_{1 / 2}$ obtained from the measured data $(5$ days) agrees well with the calculated one (4.3 days).

To further verify measurement results we calculated internal RH ( $R H_{\text {EVAcalc }}$ in Fig. 16) by numerical integration of the differential equation (1) using $W V T R_{B S}$ and $c_{s}$ data, predetermined by the Mocon test and interpolated to the actual measured temperature in the stack using Arrhenius law.

Although some simplified conditions were assumed [14], as for instance that the water concentration in the encapsulant is homogeneous, the calculated RH is in good agreement with the measurement.

Overall, the proposed method gives reliable results as long as the laminated SHT25 sensors are exposed to normal operating conditions according to Fig. 2. The data in Fig. 16 clearly shows that while environmental conditions may often be outside desired operating conditions of the sensor, the module interior is well within its operating limits. In this frame, this method can as well be applied to characterization of moisture ingress properties of PV encapsulants. Indeed, water vapor transmission rate of the backsheet $\left(W V T R_{B S}\right)$ parameter was determined as a free parameter from the fitting of the glass/EVA/backsheet RH data while diffusion coefficient of EVA, was extracted as a free parameter by fitting of the RH results for the glass/EVA/glass stack experiments.

The total thickness of the EVA layers was taken from datasheet (Table 1) and saturation water content $c_{s}=3.2 \mathrm{~kg} / \mathrm{m}^{3}$ was determined separately by a dynamic vapor sorption (DVS) experiment. Obtained material properties are summarized in Table 2.

TABLE 2

EXTRACTED MATERIAL PROPERTIES FROM RH MEASUREMENTS.

\begin{tabular}{llll}
\hline \hline Property & & Fitted value & Reference value \\
\hline \multirow{2}{*}{$\boldsymbol{V} \boldsymbol{T} \boldsymbol{R}_{\boldsymbol{B} S}\left[\mathrm{~kg} / \mathbf{m}^{2} / \mathbf{s}\right]$} & exp. & $2.2-2.6 \cdot 10^{-7}$ & \multirow{2}{*}{$3.0 \cdot 10^{-7}$} \\
\hline \multirow{2}{*}{$\boldsymbol{D}_{E V A}\left[\mathrm{~m}^{2} / \mathbf{s}\right]$} & exp. + lin. & $3.5-3.9 \cdot 10^{-7}$ & \\
\hline \hline
\end{tabular}


Obtained $W V T R_{B S}$ results are comparable to the reference value, which was determined by extrapolation using the Arrhenius law dependency from Mocon experiment at $30^{\circ} \mathrm{C}, 40^{\circ} \mathrm{C}$ and $50^{\circ} \mathrm{C}$ (see Table 1). Diffusion coefficient of EVA, extracted as a free parameter by fitting of the RH results for the glass/EVA/glass stack experiment were even closer to the extrapolated reference.

\section{CONCLUSION AND OUTLOOK}

The developed in-situ temperature and humidity monitoring method for PV modules proved to be robust and reliable. Although the applied sensors are low-costs they deliver high accuracy and extremely low noise signal readouts due to the allin-chip analog-to-digital conversion and digital calibration. Sensors proved to be resistant to lamination process conditions and are chemically stable being in direct contact to the EVA. Furthermore, they exhibit a linear relation between the $\mathrm{RH}$ readings in the EVA and the RH readings in the air. This enables us to extract the WVTR of backsheet and moisture diffusion coefficient of encapsulant by exposing appropriate stack arrangement to elevated RH and temperature conditions. Thus we can test various encapsulants, backsheets and edge sealants in different PV module configurations for material characterization, module stack comparison and even preliminary failure detection.

A similar miniaturized, low cost, low power and preferably wirelessly connected sensor system could be installed in commercial PV modules during the lamination procedure. This would allow in-situ monitoring of temperature and $\mathrm{RH}$ conditions during the entire PV module lifetime. Data could be gathered by a monitoring equipment, providing automated fault detection algorithms. Such capabilities could be even added to the already existing monitoring setups used in the general PV plant monitoring by the inverter manufacturers. Gathered data would provide valuable feedback information to manufacturers of materials and PV modules on one side and allow quick automatic fault detection to customers on the other side, even supporting warranty claims.

The main question which still has to be answered and will also be a subject of our future research is to find an empiric correlation between the RH readings of the sensors and the water content in various encapsulants. Results would represent a calibration base for a real time determination of the water content in PV encapsulants in laboratory or in field operation conditions.

\section{REFERENCES}

[1] C. Ferrara and D. Philipp, "Why Do PV Modules Fail?," Energy Procedia, vol. 15, pp. 379-387, 2012.

[2] M. M. Rahman, M. Hasanuzzaman, and N. A. Rahim, "Effects of various parameters on PV-module power and efficiency," Energy Convers. Manag., vol. 103, pp. 348358, Oct. 2015.

[3] D. Wu, J. Zhu, T. R. Betts, and R. Gottschalg, "PV Module Degradation Mechanisms under Different E nvironmental Stress Factors," in Proceedings of the 8th Photovoltaic Science Application and Technology Conference (PVSAT8), Newcastle up on Tyne, 2012, pp. 177-180.
[4] S. Kurtz, J. Wohlgemuth, T. Sample, M. Yamamichi, J. Amano, P. Hacke, M. Kempe, M. Kondo, T. Doi, and K. Otani, "Ensuring quality of PV modules," in 2011 37th IEEE Photovoltaic Specialists Conference (PVSC), 2011, pp. 000842-000847.

[5] J. H. Wohlgemuth and S. Kurtz, "Using accelerated testing to predict module reliability," in 2011 37th IEEE Photovoltaic Specialists Conference (PVSC), 2011, pp. 003601-003605.

[6] G. J. Jorgensen, K. M. Terwilliger, J. A. DelCueto, S. H. Glick, M. D. Kempe, J. W. Pankow, F. J. Pern, and T. J. McMahon, "Moisture transport, adhesion, and corrosion protection of PV module packaging materials," Sol. Energy Mater. Sol. Cells, vol. 90, no. 16, pp. 2739-2775, Oct. 2006.

[7] S. Mekhilef, R. Saidur, and M. Kamalisarvestani, "Effect of dust, humidity and air velocity on efficiency of photovoltaic cells," Renew. Sustain. Energy Rev., vol. 16, no. 5, pp. 2920-2925, Jun. 2012.

[8] B. A. L. Gwandu and D. J. Creasey, "Humidity: A factor in the appropriate positioning of a photovoltaic power station," Renew. Energy, vol. 6, no. 3, pp. 313-316, Apr. 1995.

[9] M. Koehl, M. Heck, and S. Wiesmeier, "Modelling of conditions for accelerated lifetime testing of Humidity impact on PV-modules based on monitoring of climatic data," Sol. Energy Mater. Sol. Cells, vol. 99, pp. 282-291, Apr. 2012.

[10] C. Peike, S. Hoffmann, P. Hülsmann, B. Thaidigsmann, K. A. Wei $\beta$, M. Koehl, and P. Bentz, "Origin of damp-heat induced cell degradation," Sol. Energy Mater. Sol. Cells, vol. 116, pp. 49-54, Sep. 2013.

[11] P. Hacke, S. Spataru, K. Terwilliger, G. Perrin, S. Glick, S. Kurtz, and J. Wohlgemuth, "Accelerated Testing and Modeling of Potential-Induced Degradation as a Function of Temperature and Relative Humidity," IEEE J. Photovolt., vol. 5, no. 6, pp. 1549-1553, Nov. 2015.

[12] J. A. del Cueto and T. J. McMahon, "Analysis of leakage currents in photovoltaic modules under high-voltage bias in the field," Prog. Photovolt. Res. Appl., vol. 10, no. 1, pp. 15-28, Jan. 2002.

[13] N. Park, C. Han, and D. Kim, "Effect of moisture condensation on long-term reliability of crystalline silicon photovoltaic modules," Microelectron. Reliab., vol. 53, no. 12, pp. 1922-1926, Dec. 2013.

[14] M. Kempe, "Modeling of rates of moisture ingress into photovoltaic modules," Sol. Energy Mater. Sol. Cells, vol. 90, no. 16, pp. 2720-2738, Oct. 2006.

[15] N. Kim and C. Han, "Experimental characterization and simulation of water vapor diffusion through various encapsulants used in PV modules," Sol. Energy Mater. Sol. Cells, vol. 116, pp. 68-75, Sep. 2013.

[16] T. Carlsson, J. Halme, P. Lund, and P. Konttinen, "Moisture sensor at glass/polymer interface for monitoring of photovoltaic module encapsulants," Sens. Actuators Phys., vol. 125, no. 2, pp. 281-287, Jan. 2006.

[17] G. Huyberechts and L. Frisson, "In situ formation of humidity-sensitive devices for the evaluation of solar panel encapsulations," Sens. Actuators B Chem., vol. 27, no. 13, pp. 308-311, Jun. 1995. 
[18] T. Carlsson, P. Konttinen, U. Malm, and P. Lund, "Absorption and desorption of water in glass/ethylenevinyl-acetate/glass laminates," Polym. Test., vol. 25, no. 5, pp. 615-622, Aug. 2006.

[19] "SHT-25 datasheet." [Online]. Available: http://www.sensirion.com/fileadmin/user_upload/custome rs/sensirion/Dokumente/Humidity/Sensirion_Humidity_S HT25_Datasheet_V3.pdf.

[20] "Humidity sensors with CMOSsens(R)." [Online]. Available: http://www.sensirion.com/en/technology/humidity/.

[21] "Temp-flex F30_025_IDS_Cable.pdf." [Online]. Available:

http://www.mouser.com/ds/2/276/molex_F30_025_IDS Cable-356228.pdf. [Accessed: 28-Dec-2015].

[22] D. J. Coyle, "Life prediction for CIGS solar modules part 1: modeling moisture ingress and degradation," Prog. Photovolt. Res. Appl., vol. 21, no. 2, pp. 156-172, Mar. 2013. 